\title{
Taller people should have Higher BMI's and Blood Pressure Measurements as their Normal
}

\author{
Jonathan V Roth* \\ Department of Anesthesiology, Albert Einstein Medical Center, USA
}

Received: 啙June 26, 2018 Published: 此 July 10, 2018

*Corresponding author: Jonathan V Roth, Department of Anesthesiology, Albert Einstein Medical Center, 5501 Old York Road, Philadelphia; PA 19141

\section{Introduction}

Current normal ranges for BMI and blood pressure do not account for variations in patient's height. I propose that taller patients should have as their normal a higher BMI and a higher blood pressure, and the converse for shorter people.

\section{Blood pressure}

The baroreceptor is located in a major artery supplying the brain. Assuming the goal and regulation of blood pressure is to have the same cerebral perfusion pressure in an erect patient, then the blood pressure generated at the heart (and measured at that level) will need to be greater in taller patients as the arterial hydrostatic pressure will decrease in an ascending fluid column, the column being longer in a taller patient. As a first approximation, the distance from the breasts (i.e., the level of the heart) to the top of the head is $1 / 4$ the height of person (Vitruvian Man ratios, Leonardo Da Vinci). Most adults are between 1.5 and 2.0 meters in height. For someone 1.5 meters tall (4'11'), that would be a distance $37.5 \mathrm{~cm}$; $50 \mathrm{~cm}$ for someone 2.0 meter tall $\left(6^{\prime} 7^{\prime \prime}\right)$. A height difference of $12.5 \mathrm{~cm}(=50-37.5)$ corresponds to a hydrostatic pressure gradient difference of approximately $9 \mathrm{~mm} \mathrm{Hg}$. With current discussions of whether systolic blood pressure should be treated at $140 \mathrm{mmHg}$ vs $130 \mathrm{mmHg}$ vs $120 \mathrm{mmHg}$, a difference of this magnitude may determine whether someone is treated for hypertension and if the treatment goal has been met.

Taller people need a higher blood pressure measured at the level of the heart to obtain the same cerebral perfusion pressure at the top of the cranium. It is possible that not accounting for this may put taller patients at increased risk for syncope as the unadjusted aggressive blood pressure target may be inappropriately low. The fact that the normal blood pressure in children increases as they get older, and taller, is consistent with this line of reasoning[1].

\section{BMI}

BMI is calculated as weight (a measure proportional to length [L] cubed, via density) divided by height (L) squared. If as one grows in height, much of the body also grows in width and depth, then mathematics dictate BMI increases as height increases (i.e., L3/L2 increases as $\mathrm{L}$ increases for $\mathrm{L}$ greater than 1 ). This relationship is very apparent if one inspects the pediatric charts of BMI versus age with the understanding that height increases with age. In adults, the increase in BMI with height relationship can be demonstrated by calculating the BMI as a function of weight from any of the ideal body weight formulas. For patients on the border, this may place a taller patient into a more obese category than physiology would otherwise dictate. The Corpulence Index (CI), also known as the Ponderal Index or Rohrer's Index, 1 is computed as weight divided by height cubed, and may fluctuate less with height than BMI. In medical journals, it is not commonly used for adults.

By way of example, a commonly used estimate for ideal body weight (in men) is weight (pounds) $=106$ pounds +6 pounds for every inch in height over 60 inches. Using this formula, at ideal body weight the BMI of someone $5^{\prime} 0$ " is 20.74 (CI = 13.6), while for an individual 6'7" tall, the BMI is 24.84 ( $\mathrm{CI}=12.4$ ), both within the BMI normal range of 20-25. To move into the overweight category $(\mathrm{BMI}=25)$, the 6' $7^{\prime \prime}$ patient would need to gain $0.7 \mathrm{~kg}$ in weight while the $5^{\prime} 0^{\prime \prime}$ patient would need to gain $9.9 \mathrm{~kg}$. (In other words, a 5'0" tall man could gain 20 pounds and still not be considered overweight whereas a 6'7" man need only gain 2 pounds to be considered overweight.) To move into the obese category (BMI $=30$ ), the $6^{\prime} 7^{\prime \prime}$ patient would need to gain $20.8 \mathrm{~kg}$ while the $5^{\prime} 0^{\prime \prime}$ patient would need to gain $21.5 \mathrm{~kg}$. A $21 \mathrm{~kg}$ weight gain is likely more physiologically impactful on someone 5' $0^{\prime \prime}$ compared to someone 6'7".

In summary, these considerations are relevant for patients on the border of a designated obesity category or determining whether blood pressure treatment should be initiated or if treatment goals have been met. Until there is data to support these arguments, we should consider these concerns in guidelines and treatment goals. It would be interesting if existing studies that have relevant data do a reanalysis to determine the impact of height as an independent variable. Concerning the extra work on the heart required to maintain a higher blood pressure, that may just be the cost that must be paid for being tall. Comparative physiology is full of examples of differences between animals of different sizes. 
Authors contribution: Jonathan V. Roth is responsible for everything involved in this submission.

A portion of this submission was previously included in a letter to the editor: Anesthesiology 2018; 128(2):424.

\section{ISSN: 2574-1241}

DOI: 10.26717/BJSTR.2018.06.001381

Jonathan V Roth. Biomed J Sci \& Tech Res

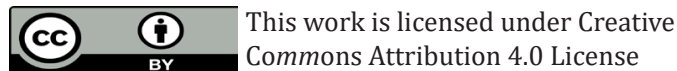

Submission Link: https://biomedres.us/submit-manuscript.php

\section{References}

1. Rohrer F (1921) The index of body fullness as a measure of nutritional status (article in German). Munchner Med Wschr 68: 580-582.

$\begin{array}{ll}\text { BIOMEDICAL } & \text { Assets of Publishing with us } \\ \text { RESEARCHES } & \text { Global archiving of articles } \\ \text { - Immediate, unrestricted online access }\end{array}$

